\title{
Study and Shutoff Experiment on Mechanical Properties of Multistage Resin Composite Ductile Cement
}

\author{
Liu Shasha ${ }^{1}$, Zhang Yanru ${ }^{2}$, Yan Haijun ${ }^{1}$, Liu Yun ${ }^{1}$, Xie Gang $^{1}$, Lu Cheng $^{3}$, Jing Jizhe ${ }^{1}$, Wei Aijun ${ }^{1}$, Qin Zhonghai ${ }^{1}$, Shi Lei ${ }^{1}$ \\ ${ }^{1}$ Engineering Technology Research Institute, Huabei Oilfield Company, Renqiu 062552, China; \\ ${ }^{2}$ Underground Gas Store Managent Agency, Huabei Oilfield Company, Langfang, Hebei, 065000, China \\ ${ }^{3}$ Erlian Branch, Huabei Oilfield Company, Xilinhot, Inner Mongolia, 026000, China
}

\begin{abstract}
In view of the traditional inorganic cement-based material hydration shrinkage caused by the impact of performance defects range of application, applying the principle of doping dispersion and compact packing, a multistage resin composite ductile cement slurry system with different temperatures was constructed. The compatibility, thickening and mechanical evaluation tests were carried out to optimize the resin type, doping amount and method. The results show that the thickening of the composite system is controllable, and the addition of resin is beneficial to improve the elastic deformation, whereas easy to pile up if adding extra amounts, and the compressive strength reduced. At the same time, adding resin first is beneficial to disperse in the cement gap. Compared with cement-based materials, the compressive strength increased $7 \%$ to $13 \%$, the elastic modulus decreased $10 \%$ to $15 \%$, and the deformation capacity increased $14 \%$ to $22 \%$. Field test shows that it has good sealing performance and remarkable effect of oil increasing and dewatering, which provides a new technical means for controlling casing leakage and ensuring its normal production.
\end{abstract}

\section{Introduction}

With the whole old oilfield entering the "three high" production stage, oilfield management focus on water drive adjustment, and the construction and development of gas storage and gas drive etc. are strengthened. The phenomenon of casing channeling and leakage in production wells is becoming more and more common; besides, the cement sheath needs to bear alternating load during oil production and gas injection. All of above puts forward higher requirements for wellbore sealing integrity [1-2].

The comprehensive performance of oil well cement stone is an important factor affecting the cementing process and cementing quality, which is mainly generated by the hydration and consolidation of inorganic silicate minerals. According to the research of Yan Peiyu et al. $[3,4]$ Oil well cement has inherent defects such as high volume shrinkage, high brittleness and insufficient durability. It forms gaps and cracks in the condition of cementation and strong impact which causes formation is channeling, hydrocarbons leaking and quality reducing of cement stone.

In order to improve the toughness and deformation capacity of cement stone, elastic materials, latex or fiber is usually added, but the effect is limited. The enhancement toughness is to sacrifice the compressive capacity of cement $[5,6]$. Studies have shown that adding emulsified resin, water emulsion and epoxy emulsion can influence the hydration and mechanical properties of cement paste $[7,8]$. However, under moderate and low temperature conditions without curing agent, only partial solidification occurs and exists in cement with the form of film and gel. In order to improve the mechanical properties such as brittleness, hardness and durability by dispersing multi-stage organic polymer resin in cement-based materials.

\section{Experiment}

\subsection{Reagent}

Grade $\mathrm{G}$ cement, dispersant, early strength agent, retarder, A-grade phenol resin (liquid), B-grade phenol resin (liquid), curing agent, C-grade phenol resin (solid), Cgrade epoxy resin (solid), distilled water, etc.

\subsection{Instruments}

High energy testing machine, rock tri-axial testing system, high temperature and pressure thickener, cement slurry mixer, channeling detector, steel cylinder, measuring cylinder, beaker, and fluidity cup. 


\subsection{Experiments}

\subsubsection{Preparation method}

The cement, multi-stage resin, distilled water, early strength agent (or retarder) and dispersant are mixed according to the proportion and order. Then they are put into the cement slurry mixer for mixing, and then the resin composite cement slurry is prepared after mixing.

\subsubsection{Thickening experiment}

Bottle test method: transfer the prepared resin-composited cement slurry system into a wide mouth bottle. After mixing evenly place it in a constant temperature water bath at the specified temperature, observe the thickening of the cement slurry, and record the time of losing flow and final setting.

Thickener method: firstly, calibrate the thickener indicator, lead the prepared resin composite cement slurry system into the thickener sample cylinder, install the potentiometer, and then put it into the thickener water bath, start the motor for thickening, set the thickening temperature, and record the consistency value of the cement slurry system at different times.

\subsubsection{Mechanical property test}

High energy testing machine method: before the experiment, the cement slurry is poured into the mold, maintained in water bath. After demoulding the standard specimen is obtained. In the experiment, the hydraulic universal testing machine is used to uniformly load the specimen at the rate of $2400( \pm 200) \mathrm{n} / \mathrm{s}$ until the maximum load is reached, and then the data are recorded to calculate the 24-hour compressive strength and elastic modulus [9].

Tri-axial test: According to the requirements of API specification the standard specimen is made using resin composite cement paste. The elastic modulus is tested by GCTS-RTR-1000 rapid rock tri-axial test system and the axial stress of rock is gradually increased to measure the breaking stress. The stress-strain relationship curve is drawn to determine the elastic modulus and Poisson's ratio of cement stone [10].

\subsubsection{Gas channeling resistance}

Put the sample into the channeling detector, set the ambient temperature and pressure difference, measure the pressure difference of gas channeling at different times during the setting process, and determine its anti gas channeling performance according to the recorded test data curve.

\section{System development}

\subsection{Resin screening}

Four kinds of multi-stage resin materials were selected and mixed with cement slurry to observe the setting process. The results show that at medium and low temperature the A / B grade resin and the cement slurry are not compatible without solidification and the $\mathrm{C}$-grade resin can meet the compatibility requirements to make finally set. At medium and high temperature, the B and C grade resin can be solidified, but the final setting time of $\mathrm{B}$-grade resin is longer ( $>5$ days). The results show that the free phenol and formaldehyde in A/ B liquid resin have great influence on the hydration of calcium silicate.

\section{2 composition and content optimization}

At different temperatures, the loss of flow and thickening time of resin composite cement slurry with different contents and components were observed. The water cement ratio was determined and the basic formula of resin composite cement was obtained. The experimental results show that when the content of $\mathrm{C}$-grade resin is less than $5 \%$ without effect on cement thickening. At the same time, the thickening time can be adjusted by early strength reagent (or retarder) which is helpful to improve the thickening reaction; the initial setting time of B-grade resin is long, which can not meet the field demand.

Table 1 Thickening experiment of resin composite cement at different temperatures

\begin{tabular}{|c|c|c|c|c|c|c|c|c|}
\hline \multirow[b]{2}{*}{ Temperature } & \multirow{2}{*}{$\begin{array}{c}\text { Water } \\
\text { Cement } \\
\text { Ratio }\end{array}$} & \multicolumn{2}{|c|}{ Resin } & \multirow{2}{*}{$\begin{array}{c}\text { Early } \\
\text { Strength } \\
\text { Agent }\end{array}$} & \multirow{2}{*}{$\begin{array}{l}\text { Fluid loss } \\
\text { Additives }\end{array}$} & \multirow[b]{2}{*}{ Dispersant } & \multirow{2}{*}{$\begin{array}{c}\text { Initial } \\
\text { Setting } \\
\text { Time }\end{array}$} & \multirow{2}{*}{$\begin{array}{c}\text { Thickening } \\
\text { Time }\end{array}$} \\
\hline & & Type & Content & & & & & \\
\hline \multirow{4}{*}{$25 \sim 50^{\circ} \mathrm{C}$} & \multirow{4}{*}{$0.7 \sim 0.8$} & - & $0 \%$ & $3 \%$ & - & $0.3 \%$ & $3.0 \mathrm{~h}$ & - \\
\hline & & $\begin{array}{l}\text { C-grade } \\
\text { Phenol }\end{array}$ & $3 \sim 5 \%$ & $3 \%$ & - & $0.3 \%$ & $2.5 \sim 3.5 \mathrm{~h}$ & $\begin{array}{c}212 \sim 248 \\
\text { min }\end{array}$ \\
\hline & & $\begin{array}{l}\text { C-grade } \\
\text { Phenol }\end{array}$ & $6 \sim 10 \%$ & $3 \%$ & - & $0.3 \%$ & $1-1.5 \mathrm{~h}$ & $\begin{array}{c}133 \sim 167 \\
\min \end{array}$ \\
\hline & & $\begin{array}{l}\text { B-grade } \\
\text { Phenol }\end{array}$ & $0.5 \sim 5 \%$ & $1 \sim 3 \%$ & - & $0.2 \sim 0.3 \%$ & $8 \sim 10 \mathrm{~h}$ & $>360 \mathrm{~min}$ \\
\hline $60 \sim 80^{\circ} \mathrm{C}$ & $0.6 \sim 0.5$ & $\begin{array}{c}\text { C-grade } \\
\text { phenol or } \\
\text { epoxy }\end{array}$ & $1 \sim 3 \%$ & $0.06 \sim 0.15 \%$ & $1 \%$ & $0.2 \sim 0.3 \%$ & $3.5 \sim 4.0 \mathrm{~h}$ & $260 \mathrm{~min}$ \\
\hline \multirow{2}{*}{$90 \sim 120^{\circ} \mathrm{C}$} & \multirow{2}{*}{0.5} & $\begin{array}{l}\text { B-grade } \\
\text { Phenol }\end{array}$ & $0.5 \sim 2 \%$ & $0.3 \sim 0.5 \%$ & $3 \sim 5 \%$ & $0.4 \sim 0.5 \%$ & $6 \sim 8 \mathrm{~h}$ & $>360 \mathrm{~min}$ \\
\hline & & $\begin{array}{l}\text { C-grade } \\
\text { Phenol }\end{array}$ & $1 \sim 3 \%$ & $0.3 \sim 0.5 \%$ & $3 \sim 5 \%$ & $0.4 \sim 0.5 \%$ & $2.5 \sim 3.0 \mathrm{~h}$ & $\begin{array}{c}117 \sim 207 \\
\min \end{array}$ \\
\hline
\end{tabular}


Initial setting time: solution lost fluidity

Final setting time: the solution become a consolidated body and resin cement

Thickening time: the consistency of cement slurry reaches $50 \sim 100 \mathrm{bc}$

\section{Evaluation of mechanical properties}

\subsection{Medium low temperature system}

The stress-strain curve of cement was tested by singleaxial universal testing machine (Fig. 1). It was shown that there was not only significant elastic deformation but also certain plastic deformation (6Mpa $>$ stress $>4 \mathrm{MPa})$.

The curve shifted to the right obviously after doping shown the toughness was significantly improved. But the compressive strength was also affected by different degrees $[11,12]$. The experimental results show that, compared with the traditional cement slurry, the comprehensive mechanical properties of the resin composite inorganic plugging agent are improved. The compressive strength increases by $7 \% \sim 13 \%$, the elastic modulus decreases by $10 \% \sim 15 \%$, and the deformation capacity increases by $14 \% \sim 22 \%$ when the content is $3 \%$.

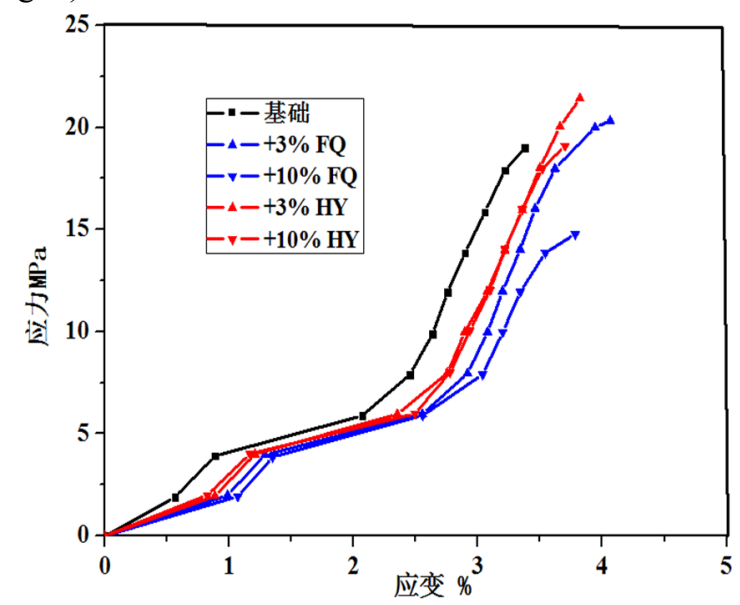

Figure 1 Stress-strain curve of low temperature system

\subsection{High temperature system}

Taking $110{ }^{\circ} \mathrm{C}$ thickening as an example, the stress-strain of composite cement was investigated by tri-axial test (table 2). Different from the medium low temperature system, its curve shows obvious elastic plastic deformation characteristics. When the stress is less than $25.4 \mathrm{MPa}$, it is approximately regarded as the elastic deformation zone; when $36.3 \mathrm{MPa}>$ stress $>25.4 \mathrm{MPa}$, it gradually approaches the elastic deformation limit; when the yield stress is reached, the stress-strain curve is close to the horizontal straight line showing significant plastic deformation characteristics.

The experimental results show that, similar to the low temperature system, the compressive strength is improved by $14.3 \%$ and the elastic modulus can be reduced by $34.8 \%$ after adding $2 \% \mathrm{C}$-grade phenol resin. Meanwhile, the SPN value is small, which indicates that the anti gas channeling effect is better.

Table 2. High temperature mechanical properties of resin composite cement

\begin{tabular}{cccccc}
\hline Temperature & Formula & $\begin{array}{c}\text { Compression } \\
\text { strength }\end{array}$ & $\begin{array}{c}\text { Elastic } \\
\text { modulus }\end{array}$ & $\begin{array}{c}\text { Poisson's ratio } \\
\mu\end{array}$ & SPN \\
\hline \multirow{2}{*}{$110^{\circ} \mathrm{C}$} & $\begin{array}{c}\text { Foundation } \\
\text { cement }\end{array}$ & $50.3 \mathrm{MPa}$ & $8.9 \mathrm{GPa}$ & 0.4 & - \\
\cline { 2 - 6 } & $\begin{array}{c}+1 \% \text { C-grade } \\
\text { phenol resin } \\
+2 \% \text { C-grade } \\
\text { phenol resin }\end{array}$ & $52 \mathrm{MPa}$ & $5.2 \mathrm{GPa}$ & 0.44 & 2.42 \\
\hline $\begin{array}{c}+3 \% \text { C-grade } \\
\text { phenol resin }\end{array}$ & $42.9 \mathrm{MPa}$ & $5.8 \mathrm{GPa}$ & 0.5 & 0.33 \\
\hline
\end{tabular}

\section{Analysis of influencing factors}

The doping method has a great influence on the thickening and mechanical properties of cement slurry $[13,14]$. As shown in Table 3, when the resin content is less than $5 \%$ it has less affect to cement thickening; the initial setting time of the later adding resin is significantly shorter than the first doping resin; the addition of resin significantly improve the elastic deformation, but the compressive strength is reduced if the amount of resin is too large ( $>$
$3 \%$ ) or later added. From the profile of cement paste (Fig. 2 ), adding resin first is beneficial to disperse resin particles in the cement gap, filling pores and making the structure more compact. However, excessive addition or later adding will easily lead to the accumulation of resin layer and poor dispersion, which will affect the comprehensive mechanical properties of cement paste. 


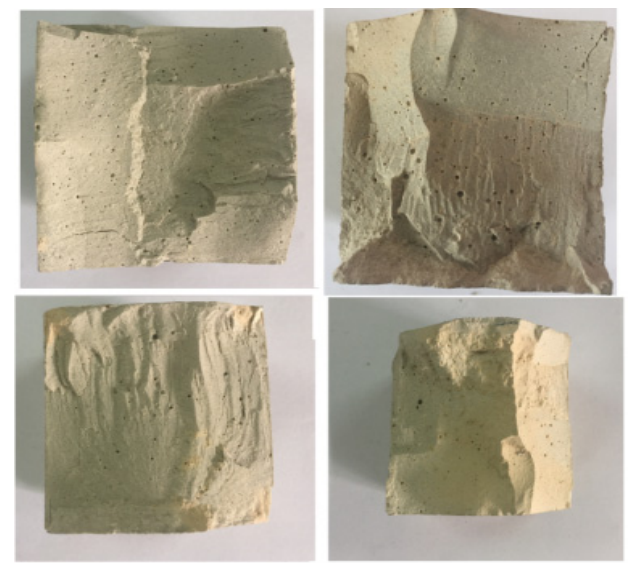

Figure 2 The profile of cement paste

Table 3 Performance evaluation of system influence factors

\begin{tabular}{cccccc}
\hline Formula & $\begin{array}{c}\text { Resin adding } \\
\text { method }\end{array}$ & $\begin{array}{c}\text { Initial Setting } \\
\text { Time }\end{array}$ & $\begin{array}{c}\text { Compression } \\
\text { strength }\end{array}$ & $\begin{array}{c}\text { Elastic } \\
\text { modulus }\end{array}$ & $\begin{array}{c}\text { Ultimate } \\
\text { deformation }\end{array}$ \\
\hline Basic fluid & - & $3.0 \mathrm{~h}$ & $18.8 \mathrm{MPa}$ & $382 \mathrm{MPa}$ & $3.40 \%$ \\
\hline$+3 \%$ FQ resin & First adding & $3.0-3.5 \mathrm{~h}$ & $20.2 \mathrm{MPa}$ & $324 \mathrm{MPa}$ & $4.15 \%$ \\
\hline$+3 \%$ FQ resin & Later adding & $1 \sim 2 \mathrm{~h}$ & $15.8 \mathrm{MPa}$ & $353 \mathrm{MPa}$ & $3.45 \%$ \\
\hline$+10 \%$ FQ resin & First adding & $1.5 \sim 2.0 \mathrm{~h}$ & $16.1 \mathrm{MPa}$ & $319 \mathrm{MPa}$ & $3.75 \%$ \\
\hline
\end{tabular}

\section{Field experiment}

In sandstone reservoir, casing sealing was carried out in 3 wells and free section sealing was carried out in 1 well. The success rate of the technology was $100 \%$, and good effect of water lowering and oil increasing was achieved.

Typical well example 1: casing channeling sealing

Well Y11 is an oil production well of Liul formation in Fushan sag. Due to water channeling outside the pipe, it causes rapid water flooding, and the daily pumping fluid is $13 \mathrm{~m}^{3}$ and the water cut is $100 \%$. Therefore sand filling is used to protect the oil layer, the upper part is perforated, and the "smooth tubing squeeze injection sealing channeling technology" is adopted to block the upper channeling section which the consumption is $15 \mathrm{~m}^{3}$ and the construction pressure is $17-25 \mathrm{MPa}$. The daily oil production increased from $4.5 \mathrm{~m}^{3}$ to $18.9 \mathrm{~m}^{3}$, and the daily water decreased from $12.9 \mathrm{~m}^{3}$ to $0.8 \mathrm{~m}^{3}$.

Typical case 2 : free section sealing

Well j331 is a water injection well in J11 fault block of Bieguzhuang oilfield. The logging shows that the casing is lost in shallow layer, and the perforating layer does not absorb water, and all injected water is lost to 475$480 \mathrm{~m}$ well section. The circulation squeeze injection process is used for plugging construction, the consumption is $10 \mathrm{~m}^{3}$, the construction pressure is $5 \mathrm{MPa}$, and the pump pressure is $3-5 \mathrm{MPa}$. After plugging, $15 \mathrm{MPa}$ pressure test was qualified, and water injection was resumed after well opening.

\section{Results}

On the basis of inorganic water plugging technology, the principle of chemical resin reinforcing cement solidification lattice gap is used, and the dispersion of multi-stage resin is doped. The compactness of cement is improved significantly including the system mechanical property.

The doping method of resin has a certain influence on the performance of the system, adding resin first in favor of dispersing in the cement gap with better comprehensive mechanical properties; however, excessive or later addition will easily lead to accumulation and affect the comprehensive mechanical properties of cement.

Field test shows that it has good sealing property and effect of dewatering increasing oil, which provides a new technical mean for casing channeling and leakage control in production wells.

\section{Reference}

1. Ju Dengfeng, Zhang Keyong, Zhang Shuangyan, The Water Shutoff Practice on Fractured Reservoirs in Huabei Oilfield[J], Fault-block Oil \& Gas Field, 2001, 8 (6) : 39-41.

2. Yan Haijun, Xie Gang, Ju Dengfeng, Technologies of chemical plugging for high water-cut horizontal wells in Jizhong District[J], Fault-block Oil \& Gas Field, 2016, 23 (5): 648-651.

3. Yan Peiyu, Yue Lei, Dai Dan, Effect of Epoxy Resin on the Hydration and Mechanical Property of Oil Well Cement Stone[J], Bulletin of the Chinese Ceramic Society, 2016, 35 (7): 2019-2023.

4. Shen Fan, Huang Shaolong, Sun Zheng, Hardening mechanism of waterborne epoxy-cementemulsified asphalt bonding system[J], Journal of Central South University(Science and Technology), 2012, 43 (1): 105-110.

5. Li He, Huang Zhiqiang, Research Progress in Improving the Toughness of Cement Stone by 
Fiber Material[J] , ,Contemporary Chemical Industry, 2018, 47 (1): 163-166.

6. Li Ming, Deng Shuang, Research on The Toughening Mechanism of Fiber/Whisker on Oil Well Cement Stone[J], Journal of Southwest Petroleum University(Science \& Technology Edition), 2016, 38 (5): 151-156.

7. Dai Dan, Yue Lei, Luo Yuwei, Effect of polymer on the microstructure and resistance to corrosion of oil well cement stones $[\mathrm{J}]$, Journal of Chinese Electron Microscopy Society, 2016, 35 (3): 235-238.

8. Gu Xiang, Research on Anti-Hydrogen Sulfide Corrosion TH Resin Cement Slurry System[M], 2012, 10 15.

9. Li Ming, Liu Meng, Mechanical properties of oil well cement stone reinforced with hybrid fiber of calcium carbonate whisker and carbon fiber[J], Petroleum Exploration and Development, 2015, 42 (1): 94-100.

10. Song Yulong, Zhang Chunmei, Modification of Toughness of Oil Well Cement by Plasma Modified Rock Asphalt[J], Bulletin of the Chinese Ceramic Society, 2016, 35 (12): 4082-4087.

11. Tian Tian, Research on Properties of Waterborne Epoxy Resin Emulsion Modified Cement Mortar[M], 2007, 3 10.

12. Wang Tao, Xu Zhongxin, The Mechnism of Epoxy Modification on Cement Mortar[J], Journal of Nanjing University of Chemical Technology, 1997, 19 (2): 26-31.

13. Luo Xiao, Yang Chunli, Yao Xiao, Study on the Improvement of Mechanical Properties of Oil Well Cement Stone by Water Emulsion Resin[J] , Journal of Oil and Gas Technology, 2010, 32 (3) : 285-289.

14. Wang Yuwu, Mo Jichun, Experiments on fiber and latex improving dynamic mechanical property of oil cement stone[J], Driuing Fluid and Completion Fluld, 2005, 22 (2) : 26-28. 